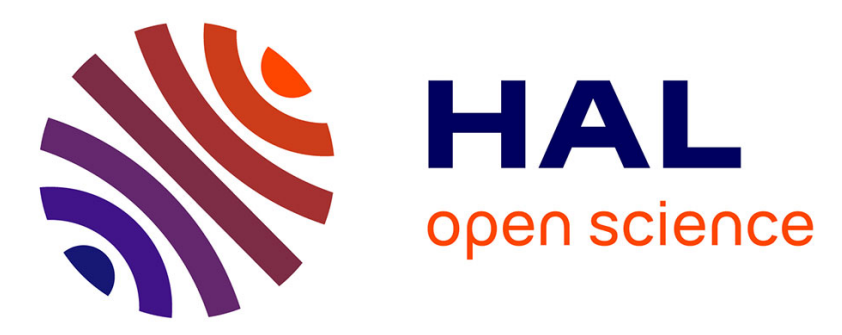

\title{
Challenges and strategies for implementing the vertical epitaxial heterostructure architechture (VEHSA) design for concentrated photovoltaic applications
}

Mark C.A. York, Antoine Mailhot, Abderraouf A Boucherif, Richard A Arès, Vincent Aimez, Simon Fafard

\section{To cite this version:}

Mark C.A. York, Antoine Mailhot, Abderraouf A Boucherif, Richard A Arès, Vincent Aimez, et al.. Challenges and strategies for implementing the vertical epitaxial heterostructure architechture (VEHSA) design for concentrated photovoltaic applications. Solar Energy Materials and Solar Cells, 2018, 181, pp.46-52. 10.1016/j.solmat.2017.11.034 . hal-01905595

\section{HAL Id: hal-01905595 \\ https://hal.science/hal-01905595}

Submitted on 8 Nov 2018

HAL is a multi-disciplinary open access archive for the deposit and dissemination of scientific research documents, whether they are published or not. The documents may come from teaching and research institutions in France or abroad, or from public or private research centers.
L'archive ouverte pluridisciplinaire HAL, est destinée au dépôt et à la diffusion de documents scientifiques de niveau recherche, publiés ou non, émanant des établissements d'enseignement et de recherche français ou étrangers, des laboratoires publics ou privés. 


\title{
Challenges and strategies for implementing the vertical epitaxial heterostructure architechture (VEHSA) design for concentrated photovoltaic applications
}

\author{
Mark C.A. York ${ }^{\mathrm{a}}$, Antoine Mailhot ${ }^{\mathrm{a}}$, Abderraouf Boucherif ${ }^{\mathrm{a}}$, Richard Arès ${ }^{\mathrm{a}}$, Vincent Aimez ${ }^{\mathrm{a}}$, Simon Fafard ${ }^{\mathrm{a}, \mathrm{b}, *}$ \\ a Laboratoire Nanotechnologies Nanosystèmes (LN2) - CNRS UMI-3463, Institut Interdisciplinaire d'Innovation Technologique (3IT), \\ Université de Sherbrooke, Sherbrooke, QC, Canada J1K OA5 \\ b Azastra Opto Inc. (now acquired by Broadcom), Ottawa, Ontario, Canada K1W 1G3
}

\begin{abstract}
Monochromatic conversion efficiencies in excess of $60 \%$ have been achieved with Vertical Epitaxial HeteroStructure Architechture laser power converters (with anywhere from 5 to $20+\mathrm{n} / \mathrm{p}$ junctions stacked vertically). We are presently investigating the applicability of this design to solar cells, whereby the individual junctions of a multi-junction cell are replaced with a current matched stack of subcells. If viable, such a design offers the potential for efficiency gains via reduced $I^{2} R$ losses and elevated $V_{o c}$. Moreover, splitting the shortcircuit current over additional junctions opens up the possibility of operation under concentration ratios otherwise considered impractical for conventional cells.
\end{abstract}

\section{Introduction}

III-V photovoltaic cells are fundamental to both laser power converters (LPCs) and concentrated photovoltaics (CPVs), and in turn, both of these technologies stand to benefit from the ability to produce higher efficiency cells. There is a growing interest in LPCs, as these can be useful to any system which requires galvanic shielding, e.g. sensory equipment [1,2], medical implants [3,4], telecommunications [5], etc. High conversion efficiencies for GaAs LPCs have been reported in the literature [6-29]. However, the Vertical Epitaxial HeteroStructure Architechture (VEHSA) technology [30-38] has presented a major breakthrough in the field, with reported conversion efficiencies just under $70 \%$ (c.f. a previous reporting of $53.4 \%$ in Ref. [9] in 2008), exceeding the approximately $65 \%$ limit stipulated in Ref. [9] for these kinds of cells.

A common goal within the CPV community is the manufacture of a solar cell with a conversion efficiency exceeding $50 \%$ [39,40], seen by many as the next major milestone. Research has focused on dilute nitrides [41], increasing the number of junctions via wafer bonding [42], perovskites [43] as well as alternative strategies oriented towards module design [44]. We would like to bridge the gap between research in LPCs and CPVs by proposing that we apply the very technology that makes VEHSA devices so efficient to CPV cells themselves, namely, stacked thin junctions. The working principle here is that splitting the photocurrent over many junctions reduces $I^{2} R$ losses and loads on the tunnel junction, allowing for the possibility of operation under high solar concentration (with the goal being in excess of 1000 suns [45]). There is an added benefit of using a vertical arrangement of thin junctions since thin layers achieve a greater Fermi level splitting [46], which on a per-junction level offers a marginal boost in $V_{o c}$ when compared to a planar arrangement of bulk cells (potentially $92 \mathrm{mV}$ per junction [38]).

The outline of this text is as follows: we will begin with an overview of VEHSA LPC devices (those used for power-over-fibre applications). Section 3 contains a presentation of how the VEHSA design would be applied to solar cells, focusing on an "enhanced" tandem cell as a specific case. Sections 4 and 5 close with a discussion and our conclusions.

\section{Overview of VEHSA monochromatic cells}

A schematic representation of a typical VEHSA device is shown in Fig. 1 (not to scale, and omitting certain window / buffer layers). These devices consist of alternating stacked GaAs n/p (n-on-p) junctions separated by AlGaAs tunnel junctions and GaInP buffer / window layers. Illumination is via a monochromatic source within the range of wavelengths where the GaAs junctions are opaque while all other layers

\footnotetext{
* Corresponding author

E-mail addresses: mark.york@usherbrooke.ca (M.C.A. York), simon.fafard@usherbrooke.ca (S. Fafard).
} 


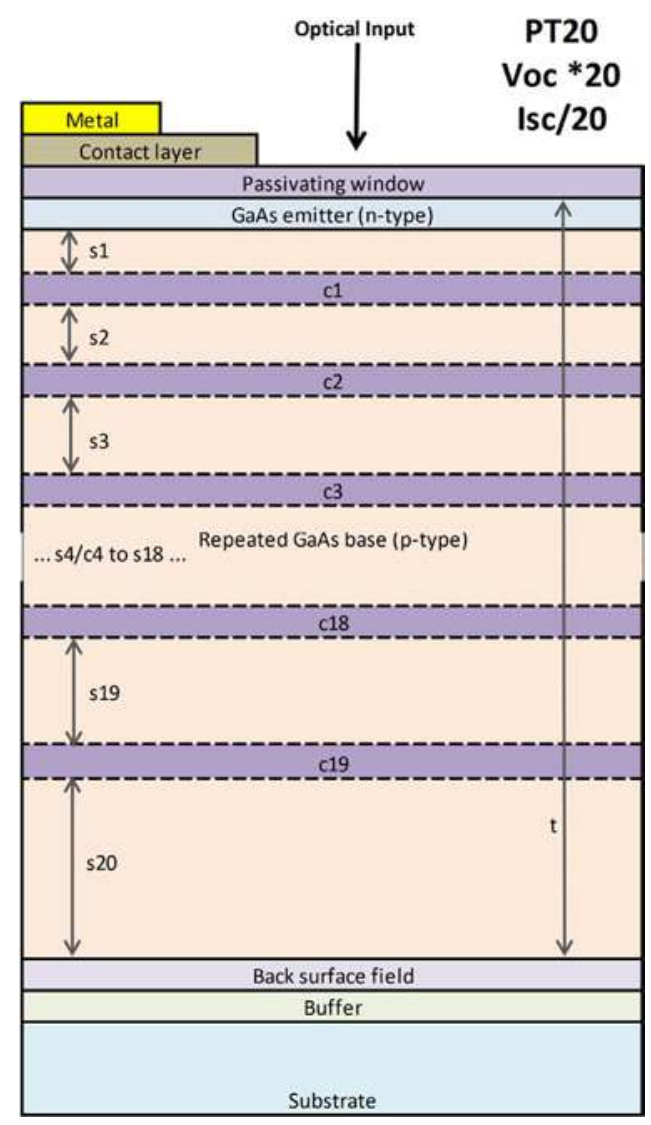

Fig. 1. A schematic of a typical VEHSA LPC (shown above for a 20 junction device). GaAs $\mathrm{n} / \mathrm{p}$ junctions are labeled s1 through s20, and tunnel junctions are $\mathrm{c} 1$ through $\mathrm{c} 19$. The topmost n-type emitter is explicitly shown, though omitted for the other subcells. Reproduced from Refs. [47,38].

(generally AlGaAs and GaInP) are transparent (in effect, the upper frequency limit is set by the band gap of the AlGaAs tunnel junctions, for an allowable range of approximately $750 \mathrm{~nm}-875 \mathrm{~nm}$, depending on the $\mathrm{Al}$ molar fraction). Since the topmost window layer is transparent to the source wavelength, we are able to employ a characteristically larger window than would be otherwise typical of multi-junction solar cells. Gridline density is assumed to be sufficient to allow for efficient carrier extraction even at high source intensities, with minimal shadowing.

VEHSA LPCs are grown via MOCVD with an Aixtron 2600 multiwafer reactor. AlGaAs $n++/ p++$ tunnel junctions are employed with $\mathrm{Al}$ fraction in the range 10\%-30\% and dopant densities exceeding $1 \mathrm{E} 19 \mathrm{~cm}^{-3}$. GaAs junctions are typically doped over the range $5 \mathrm{E} 17 \mathrm{~cm}^{-3}-1.5 \mathrm{E} 18 \mathrm{~cm}^{-3}$, with thinner junctions doped more heavily. Prior to a growth, the thicknesses of each junction are determined by initially targeting a specific wavelength (and hence uniform value of the absorption coefficient $\alpha$ in GaAs) and setting the layers such that each junction produces an equal amount of photocurrent. For a typical design wavelength of $850 \mathrm{~nm}$, total GaAs thickness may reach $3.6 \mu \mathrm{m}$ when summed over all junctions (so that the sum of the junctions is nearly fully absorbent). Due to variations in growth, the wavelength at which peak conversion efficiency is observed can generally deviate slightly from design, of the order $10 \mathrm{~nm}$.

Actual devices are known experimentally to achieve a very high degree of current matching, supplemented by photon-recycling [35] which has made it possible to consistently observe efficiencies of $60-70 \%$ for a range of devices and experimental conditions, as captured by the $I(V)$ curves in Fig. 2. Broadcom (www.broadcom.com) now offers such devices commercially, with products for various applications. With regards to the labeling PTN, $N$ represents the number of

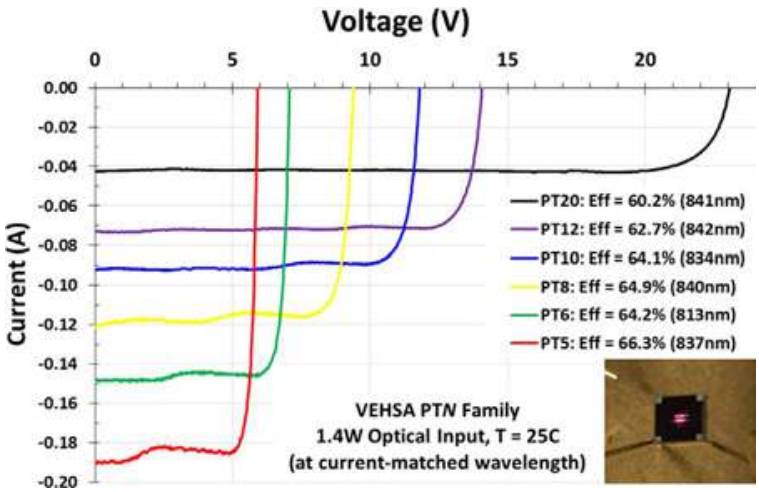

Fig. 2. $I(V)$ curves for $N=5$ up to 20 junction devices, with an illuminated cell shown in the lower right corner. Reproduced from Refs. [32,38].

junctions, i.e. PT20 contains 20 stacked junctions. Devices with over 20 junctions have also been fabricated.

Though the text focuses on solar, it is worth mentioning that we are also actively seeking to develop phototransducers with $N \gg 20$ (e.g. PT60), discussed in Ref. [38]. A tentative PT100 device would contain individual subcells as thin as $10 \mathrm{~nm}$ (noting that this value is sensitive to the wavelength chosen, and in turn should be treated as an estimate) considered to be pushing the limits of viability, though such a device is interesting in its own right due to individual junctions effectively becoming quantum wells. When individual subcells reach this size, we are additionally able to consider altering their molar composition and strain, opening up the possibility of even further enhancements of $V_{o c}$, as well as fine tuning of the absorption per subcell.

\subsection{Models}

PTN devices are simulated using Atlas, employing standard values for carrier mobilities in GaAs and GaInP, radiative recombination rates of the order $\sim 10^{-10} \mathrm{~cm}^{3} / \mathrm{s}$ and SRH lifetimes of the order $10 \mathrm{~ns}$ for both species at $1 \mathrm{E} 18 \mathrm{~cm}^{-3}$ doping (lifetimes are adjusting for doping). Parameters are tabulated in detail in Ref. [38], and these are generally consistent with other authors. Carrier lifetimes are sensitive to the quality of the crystal growth, and values obtained from the literature will not necessarily be well matched to a specific device, requiring some degree of calibration of the actual models.

In our case, all of our wafers have been grown using the same equipment, and therefore, we expect little variation of crystal quality between growths. Our models have been calibrated and exhibit very close agreement with the PV characteristics of single junction cells. The same set-up when used to model a PT12 device shows agreement with experiment at the level depicted in Fig. 3, which is still arguably a very close fit considering the random variation in layer thicknesses etc.

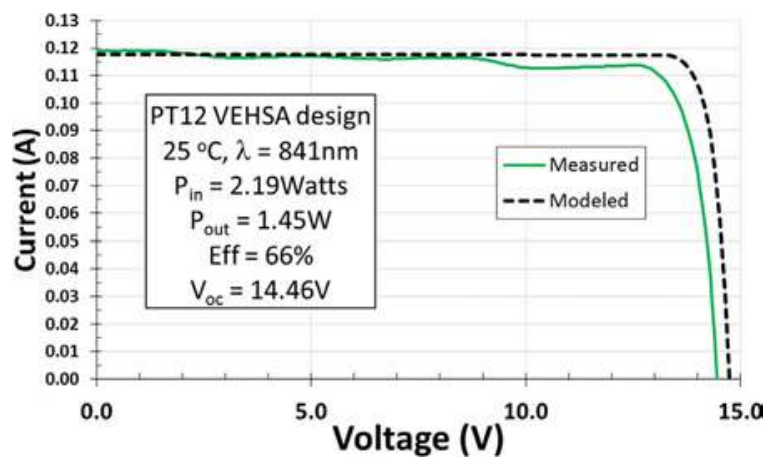

Fig. 3. Model and measured $I(V)$ curves for a PT12 cell. Reproduced from Refs. [32,37]. 

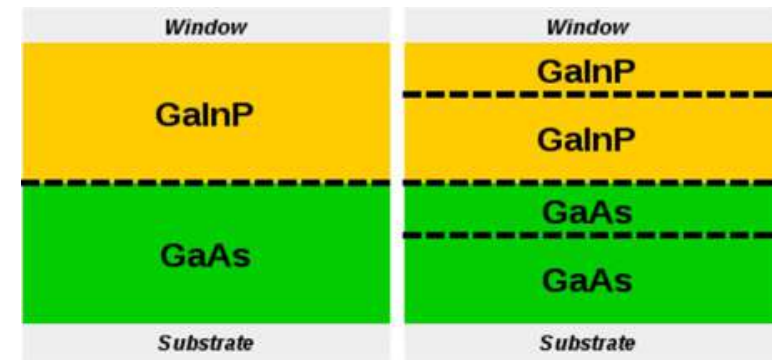

Fig. 4. A schematic of a 2 junction tandem on the left, augmented by doubling the number of junctions (while holding the total GaInP / GaAs thickness approximately fixed). For the GaInP region on the left, we refer to the corresponding 2 junction GaInP region on the right as a substack, likewise for GaAs. Dashed lines represent all of the layers that would otherwise be required between each cell, specifically back surface field, tunnel junction, and window layers.

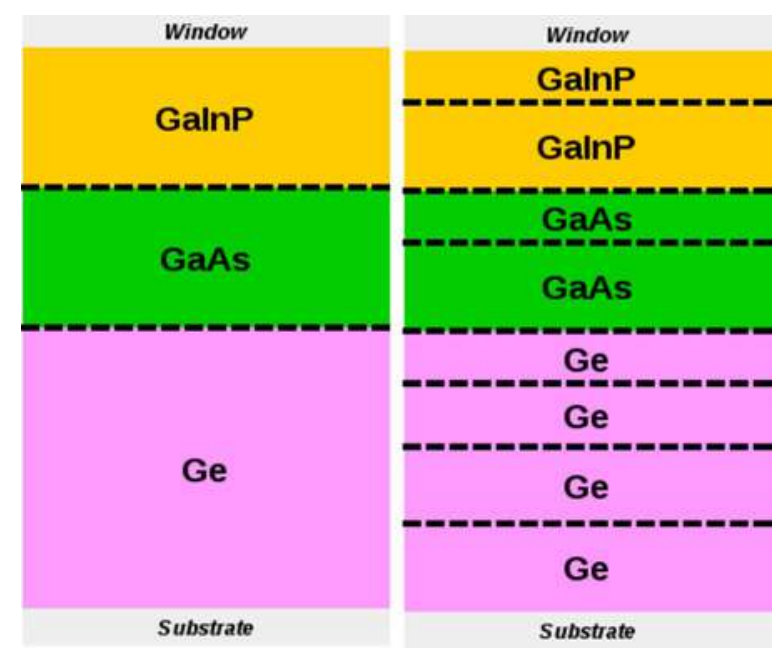

Fig. 5. Similar to Fig. 4, except illustrating a speculative enhancement of a triple junction cell.

\section{VEHSA solar cells}

Using a tandem or triple junction cell as a starting point, two possible enhancements are shown in Figs. 4 and 5. In Fig. 4 what we have done is taken a standard GaInP / GaAs tandem cell, and "duplicated" each individual junction [48]. Layers are not drawn to scale, but relative variations in thickness are illustrated, with current matching enforcing a specific ratio between upper and lower subcell thicknesses. Whereas the cell on the left of Fig. 4 comprises two subcells, the cell on the right comprises two substacks - we refer to cell on the right (and similar) as a VEHSA solar cell (noting the distinction from the VEHSA phototransducers in Section 2). A substack need not contain only 2 subcells; rather, as with the VEHSA phototransducers, the number of subcells is arbitrary, provided that subcells and substacks are current matched.

Due to the relative difference between the GaInP - GaAs bandgaps, a VEHSA tandem is current matched when (roughly) both substacks are quasi-fully-absorbing (for frequencies above each bandgap). For an actual device with 2-junction substacks (i.e. $4 \mathrm{n} / \mathrm{p}$ junctions total), this would necessitate a topmost GaInP junction thickness $\lesssim 100 \mathrm{~nm}$ (see Table A1).

Fig. 5 depicts an alternative configuration involving a Ge VEHSA substack in lieu of the usual monolithic Ge substrate (other junctions are merely shown as duplicated) for an initially triple junction cell (with the Ge as such to permit excess current recovery and better overall current matching [49]). The Ge substack as shown is somewhat speculative, as the relative thickness of these layers (compared to the III-Vs) would present challenges for growth (however, see Ref. [50]).
Also, SiGe alloys [51] can be of interest, in particular for the tunnel junctions of the lower substack.

For clarity, it should be stated that this approach is not a means to achieve revolutionary efficiency with a small number of bandgaps. Specifically, a VEHSA solar cell with a large number of junctions is not equivalent to a hypothetical multi-junction cell containing a large number of distinct bandgaps, and hence, the design presented does not approach the Shockley-Queisser with an increasing number of (single alloy) junctions. However, the VEHSA solar cell design does offer the possibility of modest increases in efficiency due to a reduction in resistive losses, as well as the potential for applications under extreme concentrations.

\subsection{Models}

Models of these devices are used primarily to assess the impact of layer thicknesses on current matching, as well as gauging the relative performance gains for VEHSA enhanced cells. Prior simulations of 2 and 4 junction monochromatic cells have been adapted to the schematic in Fig. 4, noting that in lieu of a monochromatic source, we employ an AM1.5 spectrum at concentrations $1-1000$ suns. ${ }^{1}$ Aside from differences in the alloy compositions of each layer, VEHSA solar devices also possess a significantly thinner topmost window layer when compared to PTN s. For simplicity, we assume that all window and back surface field (BSF) layers are AlInP, which reduces the number of model parameters at the expense of deviating from an actual device which would more suitably employ AlGaInP quaternaries. For the purpose of assessing trends in performance, this approximation is justified - however, any model used to infer layer thicknesses necessary for current matching necessarily requires that actual values for the refractive index of each layer be used (discussed further in the next section).

\subsection{Current matching}

As a starting point, for a given heterostructure and source spectrum (in our case AM1.5 G), short-circuit current is calculated using the BeerLambert law,

$T_{i}(\lambda)=e^{-\alpha_{i}(\lambda) t_{i}}$

where $T_{i}(\lambda)$ is the transmittance through layer $i, \alpha_{i}(\lambda)$ is the wavelength and material dependent absorption coefficient (which we have obtained from Cyrium Technologies data sets), and $t_{i}$ is the thickness of layer $i$. Integrating over the spectrum, the optimal set of junction thicknesses are obtained by adjusting the $t_{i}$ such that each junction produce the same amount of photocurrent (solved for e.g. using a Matlab based algorithm). We initially assume no loss from the AR coating.

Following this, quantum efficiency $(\mathrm{QE})$ and the reflectance are taken into account by adjusting the absorbed photocurrent in each layer as follows:

$I_{\text {abs }}=\int \frac{d I_{\text {avail }}}{d \lambda} \cdot \mathrm{QE}(\lambda) \cdot(1-T(\lambda)-R(\lambda)) d \lambda$

where $I_{a b s}$ and $I_{\text {avail }}$ are absorbed and available photocurrent respectively, suppressing the index $i$ denoting the layer. The reflectance $R$ is obtained from Fresnel equations, and transmittance $T$ is as above. $\mathrm{QE}(\lambda)$ is estimated from Ref. [52]. The advantage of this method is that non-radiative (SRH and Auger) recombination processes are represented by the albeit ad hoc QE term. However, these can be validated self-consistently following growth. One limitation is that Eq. (2) omits photon recycling from emitted photons which are reabsorbed in neighboring junctions.

\footnotetext{
${ }^{1}$ For reference, diode ideality factors have been extracted from the simulations via concentration $-V_{o c}$ dependence. We obtain a characteristic value of 1.12 for the 4 junction cell at 1000 suns (vs. unity at 1 sun). In general model values are observed to be of the order $\gtrsim 1$, increasing as a function of concentration.
} 
The optimal set of layer thicknesses for a VEHSA tandem resulting from this procedure are stated in Table A1 (which includes losses from an AR coating). Note that in constructing this table, not all layers are allowed to vary: windows, BSF and tunnel junctions are fixed in advance (which we have set at $80 \mathrm{~nm}$ ), and only the thicknesses of the actual $\mathrm{n} / \mathrm{p}$ junctions are varied. Due to the thinness of the topmost subcell, current from the window and BSF layers are including in the "total" attributed to that junction [52]. This is done for other subcells as well; however, in these cases, the contributions not arising from the actual $\mathrm{n} / \mathrm{p}$ junction layers are much smaller. Tunnel junction absorption is simulated as current loss.

To assess the impact of the QE and reflectance corrections in Eq. (2), Tables A2 to A5 compare between a simplified model of the standard and VEHSA tandem cell. Specifically, we assume no absorption from the buffer or window layers, and hence omit these entirely. For these abridged heterostructures we have calculated $J_{s c}$ and optimal layer thicknesses with and without the QE adjustment in Eq. (2): factoring in the QE represents about a $14 \%$ loss of $J_{s c}$, and a $26 \mathrm{~nm}$ adjustment to the thickness of the topmost subcell.

Lastly, the absorption spectra of both the standard and VEHSA tandems are shown in Figs. 6 and 7 for reference.

\section{Discussion}

Our benchmarks and model / experimental results for VEHSA devices have all been previously reported under monochromatic

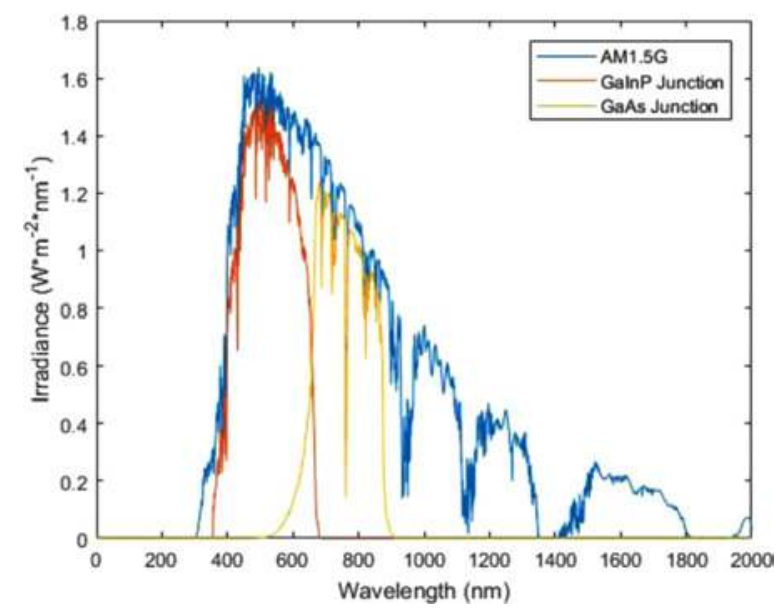

Fig. 6. AM1.5 G and simulated absorption spectra for a standard GaInP/GaAs solar cell [52].

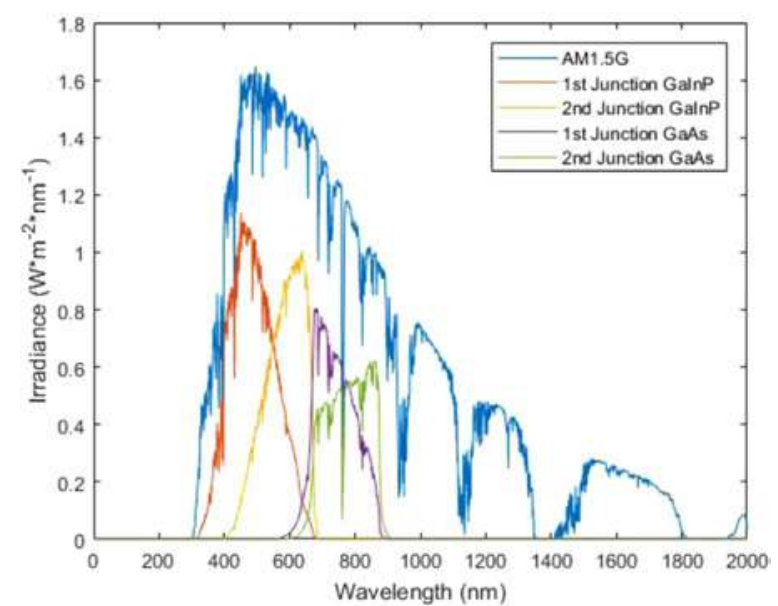

Fig. 7. AM1.5 G and simulated absorption spectra per junction for the proposed duplicated GaInP/GaAs VEHSA tandem cell (including QE and reflectance.). illumination, for which PV efficiencies are well beyond those presently attainable for multi-junction PV devices. The main reasons for this are as follows:

(i) under these conditions, thermalization losses can be minimal, since the target wavelength can be set adjacent to the band edge,

(ii) photon recycling compensates for variations in layer thicknesses (due to growth) and source detuning, which serves to redistribute photo-current between junctions.

In switching to an AM1.5 source, we would be faced with thermalization losses on par with multi-junction cells. However, we believe that the potential for enhancement due to photon recycling persists in the VEHSA solar cells, noting that:

(i) not all junctions will necessarily possess the same band-gap, therefore this opens up the possibility of additional losses from reemitted photons which are unable to excite photocurrent in the higher gap layers, in particular the thinnest topmost layers,

(ii) as such, an underperforming GaInP junction would not be compensated for by a neighboring GaAs junction, though the converse is true.

Layer thicknesses stated in Appendix A are estimated by either assuming ideal conditions (no reflections, no recombinations) or by assuming a quantum efficiency $<100 \%$ for each layer, as well as internal reflections, etc. as per the previous section. An idealized model (the former) is of interest, as it is a best case scenario, effectively an upper bound on performance. However, a realistic model (the latter) is essential to correctly specify the layer thicknesses for a growth, which unfortunately requires ad hoc input. In Section 3.2, the parameters inferred from the study in Ref. [52] are an educated guess, as the QE will in general vary between layers, depending on factors related to growth as well as doping, and can only be known precisely following growth. This raises the possibility of reduced performance from detuning: grown devices exhibiting current mismatch. Nominal layer thicknesses are computed using a nominal QE - if in fact the realized QE differs from the nominal value, then the resulting heterostructure will no longer be optimal per se. And, if in fact the performance depends strongly on the realized QE, this would necessitate an impractical finetuning of junction thicknesses.

To assess the degree of fine tuning required, we have simulated the performance of a VEHSA tandem while varying the thicknesses of individual junctions (while holding other layers fixed), for which there are two extreme outcomes: a) efficiency deteriorates rapidly with variation in layer thickness or b) efficiency is insensitive to variations in layer thickness. From inspecting Fig. 8, what we observer is that the modeled VEHSA tandem more closely falls into regime b) rather than a). Foremost, the plateau in the upper panel suggests that there is a lot of free-play in the (thinnest) topmost cell thickness, provided that it is not so thin as to reduce the fill factor. In particular, the width of the plateau exceeds the $26 \mathrm{~nm}$ difference in topmost subcell thickness when computed using lossless and lossy models of the heterostructure. In the lower panel, the peak is more pronounced, however, the dependence of efficiency on junction thickness is still fairly weak, given that a window of $1 \%$ variation in efficiency spans a thickness variation of approximately $70 \mathrm{~nm}$, well over $10 \%$ of the junction width. Therefore, it is apparent that these devices are in fact tolerant of detuning, much like what has been observed for the monochromatic PTN s.

Concerning the reproducibility of the growth process, in practice the energy gap for any binary alloys (e.g. GaAs) is very close to nominal, for example within a few meV. For the ternary InGaP, the main deviation is typically from the ordering present in this alloy. These devices are implemented on commercial reactors with demonstrated calibration and uniformities. The ordering and the alloy calibrations are controlled by the growth processes, and parameters such as growth temperature, 

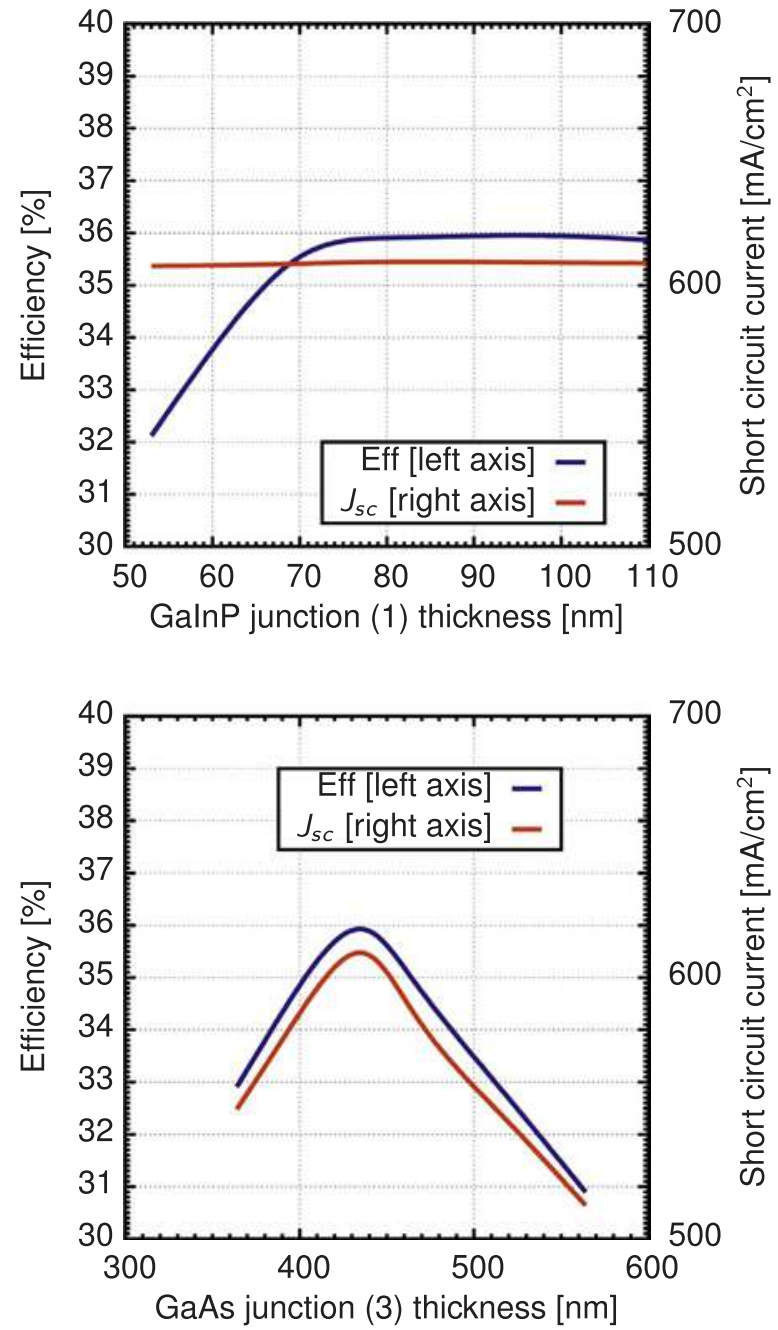

Fig. 8. Efficiency and $J_{s c}$ vs. subcell thickness, when varying the topmost GaInP and GaAs subcells (upper and lower panels respectively, modeled at 100 suns). The reduction in efficiency not matched by a reduced $J_{s c}$ in the top panel results from diminished fill factor.

III-V over-pressure, gas flux calibrations, etc. The resulting reproducible accuracy for the InGaP alloys is typically of the order of $10 \mathrm{meV}$.

Alloy variations in the window/back surface field/tunnel junction alloys have little impact because these layers are relatively thin and mostly transparent (higher bandgaps), but nevertheless can be controlled to a similar level of precision as InGaP. The layer thickness variations with state-of-the-art MOCVD reactors are typically less than $5 \%$ over the useful wafer area. The ability to achieve the nominal thickness values depends on the quality of the calibration procedure, but reproducibility at the level of $5 \%$ or better is achievable. It should also be noted that in epitaxy the most common deviation from the nominal thickness is a systematic error in the growth rate calibration, which would result in all layers being a few \% thicker or thinner than expected. Finally, deviations from nominal doping concentration in the range of $20 \%$ typically have every little impact on the overall performance of the devices, and are within the range of reproducibility of standard MOCVD operations.

The most pressing question is how much of an efficiency upgrade could the VEHSA solar methodology actually afford? A heuristic estimate would be a potential maximum increase of $3-4 \%$, assuming a $V_{o c}$ scaling on par with the observed $\sim 92 \mathrm{mV}$ per junction for PT6 devices when compared with an equivalent 6 cell planar configuration [38]. This would require multiple splittings per subcell. In simulating the VEHSA tandem, the model indicates an increase of approximately $1 \%$ under 1000 sun conditions (a jump from $36.5 \%$ to $37.6 \%$ for the modeled cell). In addition, as mentioned above, the resulting cell operation at lower currents and higher voltages can allow performance gains for solar CPV working at higher concentrations (for instance, higher $V_{o c}$ cells would be used in strings containing fewer cells, therefore reducing the losses in performance from current matching within a string, and reduced current would result in less heating of a cell through resistive losses in its window layer.)

\section{Summary and conclusions}

We have presented an overview of a preliminary analysis of the practicality of applying the VEHSA design to concentrated photovoltaic cells, including the detailed layer thicknesses and composition of a tentative VEHSA tandem cell. The impact of detuning and layer thickness errors on performance has been investigated using simulated devices, and we have observed that these devices show relatively mild sensitivity to the individual layer thicknesses of each subcell, which bodes well for the viability of this technology.

The advantage of this approach is that VEHSA solar cells possess increased $V_{o c}$ and reduced $J_{s c}$, in turn able to operate at concentrations otherwise considered high or extreme for standard cells. Heuristic estimates based on the observed performance of VEHSA phototransducers, as well as the enhanced Fermi level splitting in thin junctions suggest the possibility of efficiency gains of the order several per cent when comparing between VEHSA and stand multi-junction solar cells. Moreover, these estimates are consistent with the modeled performance of a simulated VEHSA tandem cell, for which an efficiency of $1.1 \%$ above that of the simulated standard GaInP / GaAs tandem was determined.

\section{Acknowledgments}

The authors would like to acknowledge our collaborators including the authors of Refs. [31,30,32,53,33,34,36,37,54,55], as well as all of the sources of funding in those papers, including support by the Natural Sciences and Engineering Research Council of Canada (NSERC).

\section{Appendix A. Detailed layer thickness and absorption}


Table A1

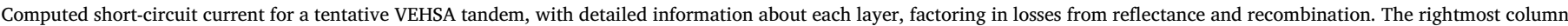
indicates the total current extracted (or lost) from each junction.

\begin{tabular}{|c|c|c|c|c|c|}
\hline Material & Type & Doping & $\begin{array}{l}\text { Thickness } \\
\text { (nm) }\end{array}$ & $\begin{array}{l}\mathrm{J}_{\mathrm{sc}}(\mathrm{mA} / \\
\left.\mathrm{cm}^{2}\right)\end{array}$ & $\begin{array}{l}\text { Total junction } \\
\mathrm{J}_{\mathrm{sc}}\left(\mathrm{mA} / \mathrm{cm}^{2}\right)\end{array}$ \\
\hline $\mathrm{SiO}_{2}$ & ARC Window & - & 100000 & - & - \\
\hline $\mathrm{Al}_{2} \mathrm{O}_{3}$ & ARC 1 & - & 90 & - & - \\
\hline $\mathrm{TiO}_{2}$ & ARC 2 & - & 50 & - & - \\
\hline $\mathrm{Al}_{40} \mathrm{Ga}_{60} \mathrm{InP}$ & Window & $\mathrm{n}+$ & 40 & 1.46 & 6.51 \\
\hline GaInP & Junction & $\mathrm{n}$ & 26 & 3.43 & \\
\hline GaInP & Junction & $\mathrm{p}$ & 27 & & \\
\hline $\mathrm{Al}_{20} \mathrm{Ga}_{80} \mathrm{InP}$ & BSF & $\mathrm{p}+$ & 80 & 1.63 & \\
\hline $\mathrm{Al}_{70} \mathrm{Ga}_{30} \mathrm{As}$ & $\mathrm{TJ}$ & $\mathrm{p}++$ & 40 & 0.03 & 0.03 (loss) \\
\hline $\mathrm{Al}_{70} \mathrm{Ga}_{30} \mathrm{As}$ & $\mathrm{TJ}$ & $\mathrm{n}++$ & 40 & & \\
\hline $\mathrm{Al}_{20} \mathrm{Ga}_{80} \mathrm{InP}$ & Window & $\mathrm{n}+$ & 80 & 0.99 & 6.50 \\
\hline GaInP & Junction & $\mathrm{n}$ & 100 & 5.50 & \\
\hline GaInP & Junction & $\mathrm{p}$ & 900 & & \\
\hline $\mathrm{Al}_{20} \mathrm{Ga}_{80} \mathrm{InP}$ & BSF & $\mathrm{p}+$ & 80 & 0.01 & \\
\hline $\mathrm{Al}_{35} \mathrm{Ga}_{65} \mathrm{As}$ & $\mathrm{TJ}$ & $\mathrm{p}++$ & 40 & 0.03 & 0.03 (loss) \\
\hline $\mathrm{Al}_{35} \mathrm{Ga}_{65} \mathrm{As}$ & $\mathrm{TJ}$ & $\mathrm{n}++$ & 40 & & \\
\hline GaInp & Window & $\mathrm{n}+$ & 80 & 0.03 & 6.56 \\
\hline GaAs & Junction & $\mathrm{n}$ & 100 & 6.51 & \\
\hline GaAs & Junction & $\mathrm{p}$ & 264 & & \\
\hline GaInp & BSF & $\mathrm{p}+$ & 80 & 0.02 & \\
\hline $\mathrm{Al}_{35} \mathrm{Ga}_{65} \mathrm{As}$ & $\mathrm{TJ}$ & $\mathrm{p}++$ & 40 & 0.0005 & 0.0005 (loss) \\
\hline $\mathrm{Al}_{35} \mathrm{Ga}_{65} \mathrm{As}$ & $\mathrm{TJ}$ & $\mathrm{n}++$ & 40 & & \\
\hline GaInp & Window & $\mathrm{n}+$ & 80 & 0.01 & 6.51 \\
\hline GaAs & Junction & $\mathrm{n}$ & 100 & 6.50 & \\
\hline GaAs & Junction & $\mathrm{p}$ & 2900 & & \\
\hline
\end{tabular}

Table A2

Maximum (best case) short-circuit current for a GaInP / GaAs tandem cell, assuming no absorption in window or buffer layers (hence these are not stated).

\begin{tabular}{|c|c|c|c|c|c|}
\hline Material & Type & Doping & $\begin{array}{l}\text { Thickness } \\
(\mathrm{nm})\end{array}$ & $\begin{array}{l}\mathrm{J}_{\mathrm{sc}}(\mathrm{mA} / \\
\left.\mathrm{cm}^{2}\right)\end{array}$ & $\begin{array}{l}\text { Total junction } \mathrm{J}_{\mathrm{sc}} \\
\left(\mathrm{mA} / \mathrm{cm}^{2}\right)\end{array}$ \\
\hline GaInP & Junction & $\mathrm{n}$ & 100 & 15.97 & 15.97 \\
\hline GaInP & Junction & $\mathrm{p}$ & 440 & & \\
\hline GaAs & Junction & $\mathrm{n}$ & 100 & 15.99 & 15.99 \\
\hline GaAs & Junction & $\mathrm{p}$ & 2900 & & \\
\hline
\end{tabular}

Table A3

Same structure as Table A2, except with $J_{s c}$ calculated under realistic conditions including recombination and reflectance.

\begin{tabular}{|c|c|c|c|c|c|}
\hline Material & Type & Doping & $\begin{array}{l}\text { Thickness } \\
(\mathrm{nm})\end{array}$ & $\begin{array}{l}\mathrm{J}_{\mathrm{sc}}(\mathrm{mA} / \\
\left.\mathrm{cm}^{2}\right)\end{array}$ & $\begin{array}{l}\text { Total Junction } \mathrm{J}_{\mathrm{sc}} \\
\left(\mathrm{mA} / \mathrm{cm}^{2}\right)\end{array}$ \\
\hline GaInP & Junction & $\mathrm{n}$ & 100 & 13.71 & 13.71 \\
\hline GaInP & Junction & $\mathrm{p}$ & 750 & & \\
\hline GaAs & Junction & $\mathrm{n}$ & 100 & 13.68 & 13.68 \\
\hline GaAs & Junction & $\mathrm{p}$ & 2900 & & \\
\hline
\end{tabular}

Table A4

Maximum (best case) short-circuit current for a GaInP / GaAs VEHSA tandem cell, assuming no absorption in window or buffer layers (hence these are not stated).

\begin{tabular}{|c|c|c|c|c|c|}
\hline Material & Type & Doping & $\begin{array}{l}\text { Thickness } \\
(\mathrm{nm})\end{array}$ & $\begin{array}{l}\mathrm{J}_{\mathrm{sc}}(\mathrm{mA} / \\
\left.\mathrm{cm}^{2}\right)\end{array}$ & $\begin{array}{l}\text { Total Junction } \mathrm{J}_{\mathrm{sc}} \\
\left(\mathrm{mA} / \mathrm{cm}^{2}\right)\end{array}$ \\
\hline GaInP & Junction & $\mathrm{n}$ & 39 & 7.94 & 7.94 \\
\hline GaInP & Junction & $\mathrm{p}$ & 40 & & \\
\hline GaInP & Junction & $\mathrm{n}$ & 100 & 8.03 & 8.03 \\
\hline GaInP & Junction & $\mathrm{p}$ & 360 & & \\
\hline GaAs & Junction & $\mathrm{n}$ & 100 & 7.99 & 7.99 \\
\hline GaAs & Junction & $\mathrm{p}$ & 230 & & \\
\hline GaAs & Junction & $\mathrm{n}$ & 100 & 8.01 & 8.01 \\
\hline GaAs & Junction & $\mathrm{p}$ & 2570 & & \\
\hline
\end{tabular}


Table A5

Same structure as Table A4, except with $J_{s c}$ calculated under realistic conditions including recombination and reflectance.

\begin{tabular}{|c|c|c|c|c|c|}
\hline Material & Type & Doping & $\begin{array}{l}\text { Thickness } \\
(\mathrm{nm})\end{array}$ & $\begin{array}{l}\mathrm{J}_{\mathrm{sc}}(\mathrm{mA} / \\
\left.\mathrm{cm}^{2}\right)\end{array}$ & $\begin{array}{l}\text { Total Junction } \mathrm{J}_{\mathrm{sc}} \\
\left(\mathrm{mA} / \mathrm{cm}^{2}\right)\end{array}$ \\
\hline GaInP & Junction & $\mathrm{n}$ & 52 & 6.84 & 6.84 \\
\hline GaInP & Junction & $\mathrm{p}$ & 53 & & \\
\hline GaInP & Junction & $\mathrm{n}$ & 100 & 6.86 & 6.86 \\
\hline GaInP & Junction & $\mathrm{p}$ & 645 & & \\
\hline GaAs & Junction & $\mathrm{n}$ & 100 & 6.84 & 6.84 \\
\hline GaAs & Junction & $\mathrm{p}$ & 250 & & \\
\hline GaAs & Junction & $\mathrm{n}$ & 100 & 6.84 & 6.84 \\
\hline GaAs & Junction & $\mathrm{p}$ & 2550 & & \\
\hline
\end{tabular}

\section{References}

[1] Worms K, Klamouris C, Wegh F, Meder L, Volkmer D, Philipps S, Reichmuth S, Helmers H, Bett A, Vourvoulakis J 2014 Lightning-safe monitoring of wind turbine rotor blades using optically powered sensors, Sensors and Measuring Systems 2014; 17. ITG/GMA Symposium; Proceedings of (VDE) pp 1-4.

[2] F.V.B. de Nazare, M.M. Werneck, IEEE Sens. J. 12 (2012) 1193-1194.

[3] A.H. Marblestone, B.M. Zamft, Y.G. Maguire, M.G. Shapiro, T.R. Cybulski, J.I. Glaser, D. Amodei, P.B. Stranges, R. Kalhor, D.A. Dalrymple, Front. Comput. Neurosci. 7 (2013).

[4] S. Park, D.A. Borton, M. Kang, A.V. Nurmikko, Y.K. Song, Sensors 13 (2013) 6014-6031.

[5] M. Röger, G. Böttger, M. Dreschmann, C. Klamouris, M. Huebner, A. Bett, J. Becker, W. Freude, J. Leuthold, Opt. Express 16 (2008) 21821-21834.

[6] V. Khvostikov, N. Kalyuzhnyy, S. Mintairov, S. Sorokina, N. Potapovich, V. Emelyanov, N.K. Timoshina, V. Andreev, Semiconductors 50 (2016) 1220-1224.

[7] S K Reichmuth, H Helmers, S P Philipps, M Schachtner, G Siefer, A.W. Bett, Progress in Photovoltaics: Research and Applications 2016.

[8] M. Steiner, J. Geisz, I. Garcia, D. Friedman, A. Duda, S. Kurtz, J. Appl. Phys. 113 (2013) 123109.

[9] A W Bett, F Dimroth, R Lockenhoff, E Oliva J Schubert, III-V solar cells under monochromatic illumination Photovoltaic Specialists Conference, 2008. PVSC'08. 33rd IEEE (IEEE) 2008, pp. 1-5.

[10] O.D. Miller, E. Yablonovitch, S.R. Kurtz, IEEE J. Photovolt. 2 (2012) 303-311.

[11] B. Behaghel, R. Tamaki, N. Vandamme, K. Watanabe, C. Dupuis, N. Bardou, H. Sodabanlu, A. Cattoni, Y. Okada, M. Sugiyama, Appl. Phys. Lett. 106 (2015) 081107.

[12] N. Vandamme, H.L. Chen, A. Gaucher, B. Behaghel, A. Lemaitre, A. Cattoni, C. Dupuis, N. Bardou, J.F. Guillemoles, S. Collin, IEEE J. Photovolt. 5 (2015) 565-570.

[13] U. Rau, U.W. Paetzold, T. Kirchartz, Phys. Rev. B 90 (2014) 035211.

[14] D. Liang, Y. Kang, Y. Huo, Y. Chen, Y. Cui, J.S. Harris, Nano Lett. 13 (2013) $4850-4856$

[15] K. Kang, S. Xie, L. Huang, Y. Han, P.Y. Huang, K.F. Mak, C.J. Kim, D. Muller, J. Park, Nature 520 (2015) 656-660.

[16] S.M. Lee, A. Kwong, D. Jung, J. Faucher, L. Shen, R. Biswas, M.L. Lee, J. Yoon, High performance ultrathin gaas solar cells Photovoltaic Specialist Conference (PVSC), 2015 IEEE 42nd (IEEE) 2015 pp 1-4.

[17] C.A. Sweet, K.L. Schulte, J.D. Simon, M.A. Steiner, N. Jain, D.L. Young, A.J. Ptak, C.E. Packard, Appl. Phys. Lett. 108 (2016) 011906.

[18] J. Kim, J. Hwang, K. Song, N. Kim, J.C. Shin, J. Lee, Appl. Phys. Lett. 108 (2016) 253101

[19] P D LeVan, A K Sood, P Wijewarnasuriya, A I D'Souza, Infrared sensors, devices, and applications v Proceedings of SPIE Vol 9220 2014, pp 922001-1.

[20] S Collin, N Vandamme, J Goffard, A Cattoni, A Lemaitre, J F Guillemoles, Ultrathin gaas solar cells with a nanostructured back mirror Photovoltaic Specialist Conference (PVSC), 2015 IEEE 42nd (IEEE) 2015 pp 1-3.

[21] U. Aeberhard, Appl. Phys. Lett. 109 (2016) 033906.

[22] L. Hirst, M. Yakes, J. Warner, M. Bennett, K. Schmieder, R. Walters, P. Jenkins, Appl. Phys. Lett. 109 (2016) 033908.

[23] S. Kabi, T. Das, D. Biswas, Phys. E: Low.-Dimens. Syst. Nanostruct. 42 (2010) 2131-2133.

[24] O. Höhn, A. Walker, A. Bett, H. Helmers, Appl. Phys. Lett. 108 (2016) 241104.

[25] E. Oliva, F. Dimroth, A. Bett, Progress. Photovolt.: Res. Appl. 16 (2008) 289-295.

[26] V Andreev, V Khvostikov, V Kalinovsky, V Lantratov, V Grilikhes, V Rumyantsev, M Shvarts, V Fokanov A Pavlov, High current density gaas and gasb photovoltaic cells for laser power beaming Photovoltaic Energy Conversion, 2003. Proceedings of the 3rd World Conference on, vol. 1 (IEEE) 2003, pp 761-764.

[27] M.P. Lumb, M.A. Steiner, J.F. Geisz, R.J. Walters, J. Appl. Phys. 116 (2014) 194504.

[28] A. Walker, O. Höhn, D. Micha, L. Wagner, H. Helmers, A. Bett, F. Dimroth, Impact of photon recycling and luminescence coupling in iii-v photovoltaic devices, SPIE
OPTO (Int. Soc. Opt. Photonics) (2015) 93580A.

[29] J. Schubert, E. Oliva, F. Dimroth, W. Guter, R. Loeckenhoff, A. Bett, IEEE Trans. Electron Devices 56 (2009) 170-175.

[30] S. Fafard, M. York, F. Proulx, C. Valdivia, M. Wilkins, R. Ares, V. Aimez, K. Hinzer, D. Masson, Appl. Phys. Lett. 108 (2016) 071101.

[31] D. Masson, F. Proulx, S. Fafard, Progress. Photovolt.: Res. Appl. 23 (2015) $1687-1696$.

[32] S. Fafard, F. Proulx, M. York, L. Richard, P. Provost, R. Arès, V. Aimez, D. Masson, Appl. Phys. Lett. 109 (2016) 131107.

[33] M. York, F. Proulx, D.P. Masson, A. Jaouad, B. Bouzazi, R. Arès, V. Aimez, S. Fafard, MRS Adv. FirstView (2016) 1-10 (ISSN 2059-8521).

[34] M.C. York, F. Proulx, D.P. Masson, A. Jaouad, B. Bouzazi, R. Arès, V. Aimez, S. Fafard, Enhanced photocarrier extraction mechanisms in ultra-thin photovoltaic gaas n/p junctions, SPIE OPTO (Int. Soc. Opt. Photonics) (2016) 97430Y.

[35] F Proulx, M York, P Provost, R Arès, V Aimez, D Masson, S Fafard, Physica status solidi (RRL)-Rapid Research Letters 2016

[36] S. Fafard, F. Proulx, M. York, M. Wilkins, C. Valdivia, M. Bajcsy, D. Ban, A. Jaouad, B. Bouzazi, R. Arès, Advances with vertical epitaxial heterostructure architecture (vehsa) phototransducers for optical to electrical power conversion efficiencies exceeding 50 percent, SPIE OPTO (Int. Soc. Opt. Photonics) (2016) 974304.

[37] S Fafard, M York, F Proulx, M Wilkins, C Valdivia, M Bajcsy, D Ban, R Arès, V Aimez, K Hinzer, Ultra-efficient $\mathrm{n}$-junction photovoltaic cells with voc $>14 \mathrm{v}$ at high optical input powers Photovoltaic Specialists Conference (PVSC), 2016 IEEE 43rd (IEEE) 2016 pp 2374-2378.

[38] M.C. York, S. Fafard, J. Phys. D: Appl. Phys. 50 (2017) 173003.

[39] M.A. Green, K. Emery, Y. Hishikawa, W. Warta, E.D. Dunlop, Progress. Photovolt.: Res. Appl. 23 (2015) 1-9.

[40] M.S. Leite, R.L. Woo, J.N. Munday, W.D. Hong, S. Mesropian, D.C. Law, H.A. Atwater, Appl. Phys. Lett. 102 (2013) 033901.

[41] M. Wiemer, V. Sabnis, H. Yuen, 43.5\% efficient lattice matched solar cells, Proc. SPIE 8108 (2011) 810804-810805.

[42] P. Chiu, D. Law, R. Woo, S. Singer, D. Bhusari, W. Hong, A. Zakaria, J. Boisvert S. Mesropian, R. King, IEEE J. Photovolt. 4 (2014) 493-497.

[43] H. Zhou, Q. Chen, G. Li, S. Luo, T.b. Song, H.S. Duan, Z. Hong, J. You, Y. Liu, Y. Yang, Science 345 (2014) 542-546.

[44] A. Imenes, D. Mills, Sol. Energy Mater. Sol. Cells 84 (2004) 19-69.

[45] B. Paquette, A. Boucherif, V. Aimez, R. Arès, Progress. Photovolt.: Res. Appl. 24 (2016) 150-158.

[46] Y. Cui, D. van Dam, S.A. Mann, N.J. van Hoof, P. van Veldhoven, E.C. Garnett, E.P. Bakkers, J.E. Haverkort, Nano Lett. 16 (2016) 6467-6471.

[47] M. Wilkins, C.E. Valdivia, A.M. Gabr, D. Masson, S. Fafard, K. Hinzer, J. Appl. Phys. 118 (2015) 143102

[48] A. Boucherif, R. Arès, P1467US0 Duplic. Sol. Cells, Provisional Pat. (2015).

[49] D J Aiken, Ingap/gaas/ge multi-junction solar cell efficiency improvements using epitaxial germanium Photovoltaic Specialists Conference, 2000. Conference Record of the Twenty-Eighth IEEE (IEEE) 2000, pp 994-997.

[50] M. Bosi, G. Attolini, Progress. Cryst. Growth Charact. Mater. 56 (2010) 146-174.

[51] Z.F. Ben, A. Bhouri, H. Mejri, M. Said, N. Bouarissa, J.L. Lazzari, d.F. Arnaud, J. Derrien, Phys. B: Condens. Matter 322 (2002) 225-235.

[52] K. Bertness, S.R. Kurtz, D.J. Friedman, A. Kibbler, C. Kramer, J. Olson, Appl. Phys. Lett. 65 (1994) 989-991.

[53] F. Proulx, M. York, P. Provost, R. Arès, V. Aimez, D. Masson, S. Fafard, Phys. Status Solidi (RRL)-Rapid Res. Lett. 11 (2017).

[54] C.E. Valdivia, M.M. Wilkins, B. Bouzazi, A. Jaouad, V. Aimez, R. Arès, D.P. Masson, S. Fafard, K. Hinzer, Five-volt vertically-stacked, single-cell gaas photonic power converter, SPIE OPTO (Int. Soc. Opt. Photonics) (2015) 93580E.

[55] M. Wilkins, C.E. Valdivia, S. Chahal, M. Ishigaki, D.P. Masson, S. Fafard, K. Hinzer, Performance impact of luminescent coupling on monolithic 12-junction phototransducers for $12 \mathrm{v}$ photonic power systems, SPIE OPTO (Int. Soc. Opt. Photonics) (2016) $97430 \mathrm{~W}$. 